\title{
Bullying and repeated conventional transgressions in Swedish schools: How do gender and bullying roles affect students' conceptions?
}

Robert Thornberg, Tiziana Pozzoli, Gianluca Gini and J un Sung Hong

The self-archived postprint version of this journal article is available at Linköping University Institutional Repository (DiVA):

http:// urn.kb.se/ resolve?urn=urn:nbn:se:liu:diva-140829

N.B.: When citing this work, cite the original publication.

Thornberg, R., Pozzoli, T., Gini, G., Hong, J. S., (2017), Bullying and repeated conventional transgressions in Swedish schools: How do gender and bullying roles affect students' conceptions?, Psychology in the schools (Print), 54(9), 1189-1201. https:// doi.org/ 10.1002/ pits.22054

Original publication available at:

https:// doi.org/ 10.1002/ pits.22054

Copyright: Wiley (12 months)

http:// eu.wiley.com/WileyCDA/ 
Bullying and Repeated Conventional Transgressions in Swedish Schools:

How Do Gender and Bullying Roles Affect Students' Conceptions?

\author{
Robert Thornberg \\ Linköping University, Sweden \\ Tiziana Pozzoli \\ University of Padova, Italy \\ Gianluca Gini \\ University of Padova, Italy \\ Jun Sung Hong \\ Wayne State University, U.S. \\ Sungkyunkwan University, South Korea
}

Author Note

Robert Thornberg, Department of Behavioural Sciences and Learning, Linköping University; Tiziana Pozzoli, Department of Developmental and Social Psychology, University of Padova; Gianluca Gini, Department of Developmental and Social Psychology, University of Padova; Jun Sung Hong, School of Social Work, Wayne State University.

This research was partially supported by a grant awarded to Robert Thornberg from The Swedish Research Council. We thank Rebecca Alamaa and Noor Daud, both with MAs in Psychology, for translating the ICU scale into Swedish and Sven Knutsen, MA in Sociology, for back-translating it into English.

Corresponding author: Robert Thornberg, PhD, Professor, phone: 4613 282118, e-mail: robert.thornberg@liu.se, address: Department of Behavioural Sciences and Learning, Linköping University, SE-58183 Linköping, SWEDEN 


\begin{abstract}
Bullying is a moral transgression. Recognizing the importance of approaching bullying from a moral perspective, the present study examines whether children's judgments and reasoning to justify their judgments differ between bullying and repeated conventional transgressions. Our study also explores differences by gender and differences among bullies, victims and uninvolved students. Participants included 381 students from thirteen elementary schools in Sweden. Findings indicate that children judge bullying as more wrong than repeated conventional transgressions; use moral reasons more frequently in their justifications about bullying than about repeated conventional transgressions; and use conventional reasons more frequently to justify their judgments on repeated conventional transgressions as compared with bullying. Female students and non-bullies judged bullying and repeated conventional transgressions as more wrong and used moral reasons more frequently in their justifications of judgments of bullying than did male students and bullies. Male students reported bullying more than did female students. Implications for practice are also discussed.
\end{abstract}

Keywords: social domain theory; bullying; transgression judgment; moral reasoning 
Bullying and Repeated Conventional Transgressions in Swedish Schools:

How Do Gender and Bullying Roles Affect Students' Conceptions?

Bullying is a serious societal problem with documented harmful consequences. Bullying victims are at a heightened risk of developing psychosomatic symptoms and psychological health problems such as depression, low self-esteem, anxiety, and suicidal ideation and behavior (Farrington, Lösel, Ttofi, \& Theodorakis, 2012; Gini \& Pozzoli, 2013; Reijntjes, Kamphuis, Prinzie, \& Telch, 2010). Because bullying is characterized by repeated harmful intention towards someone in a weaker position, it can be conceived as a moral transgression (Thornberg, Birberg Thornberg, Alamaa, \& Daud, 2016). Therefore, it is important to approach bullying from a moral perspective in addition to other perspectives. The present study aims to replicate previous studies by exploring whether children's judgments and reasoning to justify their judgments differ between bullying and repeated conventional transgressions in hypothetical situations. In addition, we explored possible gender differences as well as those among bullies, victims and children not involved in bullying regarding their judgments and reasoning for justifying their judgments.

\section{Morality and Social Conventions}

Morality is defined as conceptions of human welfare, justice and rights, and regulation of actions that affect others in these terms (Nucci, 2001). Social domain theory (Nucci, 2001; Turiel, 1983) postulates that children's social experiences influence the development and construction of their social knowledge in varying domains. Domains have been defined as cognitive structures developed and "organized within the boundaries of fundamental categories" (Turiel, 1983, p. 20), such as logical-mathematical thinking, moral judgment and others. The moral domain is constructed and developed through experiences of actions that have effects on the welfare of others or oneself, from the positions of being a victim, perpetrator, or witness. 
Hence, these repeated social interactions, characterized by actions causing harm to other people, shape the moral domain structures that then become latent mental structures. These latent structures, if activated, inform and influence social information processing in a given situation (Arsenio \& Lemerise, 2004). In contrast to morality, social conventions are based upon traditions, authority, and customs, and provide individuals with social norms and expectations regarding appropriate behavior in different social contexts. The actions they regulate do not include harm to other people (Nucci, 2001; Turiel, 1983).

Previous research has shown that, from early preschool years, children distinguish between morality and convention. For example, they judge moral transgressions as wrong, regardless of whether rules exist, and as more seriously wrong than conventional transgressions. Moreover, children and adolescents tend to justify their judgments of moral transgressions in terms of the harm or unfairness these actions cause. On the other hand, they tend to justify their judgments of conventional transgressions by referring to social norms/rules, social expectations, customs, traditions, authorities, and social arrangements (Nucci, 2001). In line with the social domain theory, children consider bullying as highly immoral, wrong independent of the rules, and worse than conventional transgressions. They justify these judgments by referring to the harm bullying causes (Thornberg, 2010; Thornberg et al., 2016). Thornberg et al. (2016) examined 307 elementary students' judgments and reasoning about bullying and repeated conventional transgressions when school rules regulating such behaviors were removed. The students responded to twelve vignettes (hypothetical scenarios occurring in a school). Eight of them represent various bullying situations and four represent various repeated conventional transgressions (e.g., swearing, or speaking while the teacher was talking). The students were asked to judge the behavior in each vignette as well as to justify their judgment through an open- 
ended question. We used Thornberg and colleagues (2016) vignettes but also examined whether there were possible gender differences or variations among bullies, victims and uninvolved students in judging and justifying their judgments of bullying as opposed to their judgments of repeated conventional transgressions.

\section{Gender Differences in Transgression Judgment and Judgment Justification}

In general, both male and female students tend to judge moral transgressions as more wrong than conventional transgressions, and use moral reasons to explain their judgments of moral transgressions. They refer to conventional reasons in justifying how they judge conventional transgressions (Nucci, 2001). However, findings on gender differences in this field have been inconsistent. Some studies have found female students to be less accepting than male students toward breaking both moral (Caravita, Giardino, Lenzi, Salvaterra, \& Antonietti, 2012; Caravita, Gini, \& Pozzoli, 2012) and conventional rules (Caravita, Giardino, et al., 2012; Caravita, Miragoli, \& Di Blasio, 2009). In contrast, other research did not find any gender differences in students' ratings of the seriousness of moral and conventional transgressions (Banerjee, Bennett, \& Luke, 2012), or in accepting moral transgressions (Caravita et al., 2009). Specifically considering the moral domain, other studies have revealed that male students are more likely than female students to judge aggression (e.g., Rose \& Rudolph, 2006), including bullying (Boulton, Bucci, \& Hawker, 1999), as less wrong. In general, male students are more apt to engage in bullying (for a meta-analysis, see Cook, Williams, Guerra, Kim, \& Sadek, 2010) and display less empathy (Jolliffe \& Farrington, 2006a; Garaigordobil, 2009), greater moral insensitivity (You, Maeda, \& Bebeau, 2011) and fewer emotion recognition skills (Maguire, Niens, McCann, \& Connolly, 2016), and higher levels of moral disengagement (Gini, Pozzoli, \& Hymel, 2014) than female students. The core of moral reasoning refers to harm and well-being 
(Nucci, 2001; Turiel, 1983), and it is likely that female students would be more likely than male students to use moral reasons when justifying their judgments about bullying).

\section{Differences in Transgression Judgment and Justification of Judgment among Bullying}

\section{Subgroups}

A recent meta-analysis revealed that, among children and adolescents, the more frequently conduct problems arise, the greater likelihood of bullying (Kljakovic \& Hunt, 2016), suggesting that youth who bully more often than peers also tend to violate rules and display oppositional and other types of antisocial behavior. Conduct problems entail "the violation of the basic rights of others, societal norms or rules" (Baker, 2013, p. 24), including aggression,

property destruction, lying for personal gain, stealing, and serious rule violations (Baker, 2013). In a number of longitudinal studies, bullying has also been found to predict delinquency, criminality, and other antisocial behavior in adolescence and adulthood (Farrington et al., 2012). The higher prevalence of conduct problems and antisocial behavior among bullies, including aggression and rule violation in general, might indicate a greater acceptance of both moral and conventional transgressions, compared to non-bullying peers. Supporting this proposition, De Angelis, Bacchini and Affuso (2016) have recently shown that among adolescents, greater bullying was associated with a weaker tendency of judging both moral and conventional transgressions as wrong.

\section{Study Hypotheses}

Based on previous research, we proposed the following hypotheses about transgression judgments and judgment for the whole sample independent of the actual role played in bullying. In a hypothetical school context in which rules that regulate the pertinent behaviors have been removed, children are likely to (1) judge bullying as more wrong than repeated conventional 
transgressions; (2) use moral reasons more frequently in their justifications of how they judge bullying, compared to how they judge repeated conventional transgressions; (3) use conventional reasons more frequently in their justifications of the judgments they make of repeated conventional transgressions, compared to those about bullying; (4) use moral reasons more frequently than conventional reasons in their judgments of bullying, and (5) use conventional reasons more frequently than moral reasons in their judgments of repeated conventional transgressions.

In addition, we tested possible gender differences, hypothesizing that: in a hypothetical school context in which rules that regulate the pertinent behaviors have been removed, (6) female students are more likely to judge bullying as more wrong than male students; (7) female students are more likely to judge repeated conventional transgression as more wrong than male students; (8) female students are more likely to use moral reasons more frequently in their justifications of judgments of bullying than male students, and (9) male students are more likely to be engaged in bullying than are female students.

Finally, it is reasonable to postulate that judgements and justifications of moral and conventional transgressions differ according to the role children play in the bullying process. Therefore, our final hypotheses examined group differences among bullies, victims, and children uninvolved in bullying. More specifically, in a hypothetical school context in which rules that regulate the pertinent behaviors have been removed, we expected that (10) bullies are more likely to judge bullying as less wrong than victims and uninvolved peers; (11) bullies are more likely to judge repeated conventional transgressions as less wrong than victims and uninvolved peers, and (12) bullies are more likely to use moral reasons less frequently in their justifications of judgments of bullying than do victims and uninvolved peers. 


\section{Method}

\section{Participants}

Participants were recruited from thirteen elementary schools (eleven public schools and two private schools) in Sweden, using a non-probability two-step sampling process. In the first step, thirteen schools were included through a purposive sampling of schools, which resulted in the inclusion of two schools in the countryside, one school in a small town, one school in a largesized Swedish city, and nine schools in different neighborhoods within two medium-sized Swedish cities. In the next step, we conducted a convenience sampling of students in grade 5-6 in each school was conducted. These grades were selected because Swedish national surveys have reported the highest prevalence of bullying in this age group of students (Swedish National Agency for Education, 2016). The original sample consisted of 458 students. Parental consent letters were sent to all the families. In addition to obtaining parental consent, we asked all of the participants for consent. Twenty-four students did not participate because they chose not to or because they did not obtain parental consent. Thirty-two students did not participate because they were ill when the data were collected. Furthermore, 21 students were excluded from the analyses because of missing data (more than $50 \%$ of missing data in the entire questionnaire or in each single scale). Given the small number of missing data among the included participants (5.25\% cases and $0.33 \%$ values), a simple mean imputation was performed (i.e., each missing value was replaced with the mean of the observed values for the actual variable). The final sample consisted of 381 students (183 females and 198 males; 175 in grade 5 and 206 in grade 6; age range $=10.0-13.5$ years, $M=12.0, S D=.73)$, resulting in a participation rate of $83.2 \%$.

\section{Procedures}


The participants completed an anonymous questionnaire during an entire class lesson in their regular classrooms. Trained graduate students in psychology were present in the classrooms during the survey administration (one graduate student in each classroom). They explained the study procedure, reassured students that their participation was confidential, and assisted those who needed help. They also assured participants that they could withdraw from the study at any time. To ensure anonymity, the participants were instructed to move away from each other and separate their desks. The procedure took about 20 to 30 minutes in each classroom. The study received ethical approval from the Regional Ethical Review Board at Linköping, which is similar to the Institutional Review Board.

\section{Measures}

Hypothetical scenarios. The first part of the questionnaire was adopted from Thornberg and colleagues (2016), a modified and expanded version of the questionnaire used in Thornberg (2010). On the first page, this introductory text was presented: "This questionnaire is about a school, called Aspen Grove School, and it is like your own school. There are many rules at Aspen Grove School. Here are some examples of rules that Aspen Grove School has", followed by a list of rules (e.g., be quiet in classroom during deskwork, don't swear when talking; see Thornberg et al., 2016 for the full list)

The list of school rules was followed by a general statement and a few instructions, "Now the teachers at Aspen Grove School have decided to take away some rules at the school. In this questionnaire, we ask you what you think about this. When you answer, try to ignore what the teachers or other adults at your school think. We want to know what you as a student think". After this instruction, twelve vignettes (hypothetical scenarios) that occurred in school were presented, describing both prototypical examples of bullying (i.e., cases of repeated moral 
transgressions) and repeated conventional transgressions. Thus, to control for the repeated nature of bullying behavior, conventional transgressions were portrayed as repeating over time. The structure of each vignette was similar: beginning with the teachers telling the students of the fictional school that a specific school rule has been repealed. Later, the scenario describes an incident in which one or more students behaved in the way that was previously forbidden by the repealed rule. Specifically, four vignettes represent direct bullying (two for physical bullying and two for verbal bullying), four vignettes represent relational bullying (two for negative rumorspreading and two for ostracizing), and four vignettes represent repeated conventional transgressions. Below is an example of a physical bullying vignette from the questionnaire.

The teachers told the students that they have taken away the rule about no beating one another. During the next months, some students are beating the same student during the breaks, several times a week.

The direct bullying stimuli were "beating" $\left(\mathrm{DB}^{1}\right)$, "teasing" $\left(\mathrm{DB}^{2}\right)$, "verbal threating" $\left(\mathrm{DB}^{3}\right)$, and "hair pulling" $\left(\mathrm{DB}^{4}\right)$. The relational bullying stimuli were "spreading false rumor about theft" $\left(\mathrm{RB}^{1}\right)$, "ignoring the student" $\left(\mathrm{RB}^{2}\right)$, "excluding the student from the football game" $\left(\mathrm{RB}^{3}\right)$, and "spreading false rumor" without a specific content $\left(\mathrm{RB}^{4}\right)$. The repeated conventional transgression stimuli were "talking during seatwork" $\left(\mathrm{C}^{1}\right)$, "swearing” $\left(\mathrm{C}^{2}\right)$, “wearing a cap in classroom" $\left(\mathrm{C}^{3}\right)$, and "speaking when teacher is talking to the class" $\left(\mathrm{C}^{4}\right)$. In order to cope with the order effect and carry-over effect, we used an A-B-C-B-C-A-A-C-B-C-B-A research design, which means that the twelve vignettes were presented in following order: $\mathrm{RB}^{1}, \mathrm{C}^{1}, \mathrm{DB}^{1}, \mathrm{C}^{2}, \mathrm{DB}^{2}$, $\mathrm{RB}^{2}, \mathrm{RB}^{3}, \mathrm{DB}^{3}, \mathrm{C}^{3}, \mathrm{DB}^{4}, \mathrm{C}^{4}$, and $\mathrm{RB}^{4}$.

Bullying and conventional transgression judgments. As in Thornberg's (2010) and Thornberg and colleagues' (2016) studies, the participants were asked to judge the behavior of 
the transgressor(s) after each vignette, using a five-point scale, from $0=$ "absolutely $\mathrm{OK}$ " to $4=$ "very bad" (Thornberg, 2010). We performed an exploratory principal component factor analysis on children's responses to the twelve scenarios, using maximum likelihood, rotated using Oblimin with Kaiser normalization. Two factors with eigenvalues greater than 1.00 emerged. The factor structure was distinct and reliable $(\mathrm{KMO}=.84)$. Consistent with the social domain theory, the eight judgments of the repeated moral transgressions (i.e., bullying scenarios) loaded into one factor and the four judgments of the repeated conventional transgressions loaded into another factor. Cronbach's alpha reliability across the judgments of repeated moral transgressions (bullying) was .77 and .74 for the judgments of repeated conventional transgressions. A global index of bullying judgment was therefore computed as the mean of the transgression judgment ratings of the eight bullying vignettes. A global index of repeated conventional judgment was the mean of the transgression judgment ratings of the four repeated conventional transgression vignettes.

Reasons for transgression judgments. In order to assess justifications of their transgression judgments, the students were asked an open-ended question to provide reasons for each judgment, "Why do you think so? I think so " (followed by five blank lines). Working together, two raters coded the reasons, adopting the coding scheme used in Thornberg (2010), which consists of moral, structuring, protecting, indifference, socio-normative, personal choice, pleasure, impulse, and other reasons. Moral reasons refer to the effects of the action on the well-being of the others, to point to the harmful or unfair consequences that the behavior have for others. Structuring reasons refer to the need to maintain the activity such as a lesson, or promote the smooth running of the social group during the activity. Protecting reasons refer to preventing self-harm or accidental injury. Indifference reasons refer to the insignificance, 
meaningless or arbitrariness of a rule in itself. Socio-normative reasons refer to an individual's preferences or prerogatives, that is, it is up to the people involved to decide for themselves. Pleasant reasons refer to pleasure, wants or amusement, having fun or avoiding boredom, difficult circumstances or other unpleasant things. Impulse reasons refer to a lack of impulse control in a situation and inability to impose self-control or a spontaneous act without thinking. Other reasons refer to various reasons, such as negative role modeling, bad influence, etc. (for a more detailed description of the content of reason categories, see Thornberg, 2010, Table 2). Disagreements were discussed until a consensus was reached and then the consensus was coded. This negotiated consensus procedure of coding coordination through mutual adjustment (Hall, Long, Bermbach, Jordan, \& Patterson, 2005) enhances the coding reliability, compared with coding by a single coder. For the analyses, only the presence of moral reasons and conventional reasons were used. According to the social domain theory (Nucci, 2001; Turiel, 1983), moral reasons are based on conceptions of human welfare, justice and rights, which are a function of the inherent features of interpersonal relations and produce moral judgements about unprovoked harm or unfair treatment. Conventional reasons, in turn, are based on conceptions of agreedupon uniformities, regulations and smooth running of activities and depend on authority, traditions, customs or consensus and are determined by the social system in which they are formed. A written response was coded as conventional reasons if it consisted of at least one of the following reasons: socio-normative reasons, structuring reasons or indifference reasons. (Nucci \& Herman, 1982; Nucci \& Weber, 1995; see Table 1). Coder reliability of the moral and conventional reasoning codes was checked on a random subsample (90 participants) of the total sample. The written data in these cases was coded by a third rater (the first author), and a comparison of the two coding outcomes revealed $97 \%$ agreement. 
A global index of moral reasons in bullying was calculated by using the sum of the presence of moral reasons across the eight bullying vignettes (i.e., eight dichotomous variables in which $0=$ absence of moral reasons, and $1=$ presence of moral reasons) divided with two. For example, if a participant had used moral reasons in six of the eight bullying vignettes, the value of the "moral reasons in bullying" variable would be three $(6 / 2=3)$. If a participant instead used moral reasons in all eight bullying vignettes, the variable value would instead have been four $(8 / 2=4)$. A global index of conventional reasons in bullying was calculated by using the sum of the presence of conventional reasons across the eight bullying vignettes, which were also divided by two. A global index of moral reasons in repeated conventional transgressions was calculated by using the sum of the presence of moral reasons across the four repeated conventional vignettes. For example, if a participant had used moral reasons in three of the four vignettes, the value of the "moral reasons in repeated conventional transgressions" variable would be three. If a participant instead used moral reasons in all four bullying vignettes, the value of the variable would instead have been four. A global index of conventional reasons in repeated conventional transgressions was calculated by using the sum of the presence of conventional reasons across the four repeated conventional vignettes. The reason why the sum was divided by two when constructing the first two variables (based on eight vignettes) was to make them comparable with their corresponding variables in the repeated conventional transgression condition (based on four vignettes), a process that was for testing hypotheses $2-3$.

Bullying and peer victimization. The Swedish version (Olweus, 1996a) of the Revised Olweus Bully/Victim Questionnaire (OBVQ; Olweus, 1996b) was used to measure frequency of bullying and peer victimization. The response "two or three times a month" was used as the cutoff point (Solberg \& Olweus, 2002); that is, participants who reported being bullied two to three 
times a month or more often (but not reporting bullying others that often) were coded as "victims" $(N=69)$. Participants who reported bullying others two or three times a month or more often (independently of reporting being bullied that often or not) were coded as "bullies" $(N=$ 30; in this bully sample, 18 participants were "pure" bullies and 12 participants were bully/victims. Because of the small sample size in these two sub groups, we merged them into one bully group). Participants who did not report being bullied or bullying others two to three times a month or more often were categorized as "uninvolved" $(N=281)$.

\section{Calculating Effect Size}

When we performed independent ANOVAs and Welch $F$, Cohen's $d$ was calculated as effect size, based on means and standard deviations. In repeated ANOVAs, both partial eta square and Cohen's $d_{z}$ (the latter was calculated from $t$-value using a dependent $t$-test and $N$; see Lakens, 2013) have been reported to make comparing effect sizes across the outcomes easier.

\section{Results}

\section{Judgments across the Transgression Conditions and Reasoning for Judgments in Bullying}

Mean responses for each transgression condition (Bullying and Repeated Conventional Transgression) were analyzed using a one-way ANOVA with repeated measures on transgression judgments across the two transgression conditions (bullying judgment: $M=3.67$, $S D=.42$; judgment of repeated conventional transgressions: $M=2.29, S D=.82$ ). Results indicated that the students judged bullying as more wrong than repeated conventional transgressions $\left(F[1,380]=1390.19, p<.001, \eta_{p}^{2}=.79\right.$, Cohen's $\left.d_{z}=1.91\right)$.

The use of moral reasons in justifying judgments of bullying and repeated conventional transgressions were analyzed using a one-way ANOVA with repeated measures. The results revealed that moral reasons were significantly more frequent when justifying judgments of 
bullying $(M=2.80, S D=1.17)$ than when justifying judgments of repeated conventional transgressions $\left(M=.33, S D=.56 ; F[1,380]=1597.47, p<.001, \eta_{p}{ }^{2}=.81\right.$, Cohen's $\left.d_{\mathrm{z}}=2.05\right)$.

Moreover, the use of conventional reasons in justifying judgments of bullying and repeated conventional transgressions were analyzed using a one-way ANOVA with repeated measures. The results revealed that conventional reasons were significantly more frequent when justifying judgments of repeated conventional transgressions $(M=3.06, S D=1.25)$ as opposed to justifying judgments of bullying $\left(M=.69, S D=.79 ; F[1,380]=1116.99, p<.001, \eta_{p}{ }^{2}=.75\right.$, Cohen's $\left.d_{z}=1.71\right)$.

Finally, we examined justifying judgments within each condition, using two one-way ANOVAs with repeated measures, one for each condition. The results of the first ANOVA revealed that moral reasons $(M=2.80, S D=1.17)$ were significantly more frequent than conventional reasons $(M=.69, S D=.79)$ when justifying judgments of bullying $(F[1,380]=$ $577.00, p<.001, \eta_{p}^{2}=.60$, Cohen's $\left.d_{z}=1.23\right)$. The results of the second ANOVA showed that conventional reasons $(M=3.06, S D=1.25)$ were significantly more frequent than moral reasons $(M=.33, S D=.56)$ when justifying judgments of repeated conventional transgressions $(F[1$, $380]=1424.76, p<.001, \eta_{p}^{2}=.79$, Cohen's $\left.d_{z}=1.93\right)$.

\section{Gender Differences}

We analyzed gender differences in transgression judgments and justifying judgments of bullying and repeated conventional transgressions using a series of one-way ANOVAs (see Table 2). Levine's test indicated that the assumption for equality of variances was violated for bullying judgments, moral reasons in bullying, and bullying perpetration. Therefore, we used Welch $F$ for these. The analyses revealed that female students were significantly more prone than male students to judge bullying as wrong ( $p<.001$, Cohen's $d=.44)$, use moral reasons 
when justifying their bullying judgments $(p<.001$, Cohen's $d=.36)$. Male students were significantly more engaged in bullying ( $p<.001$, Cohen's $d=.38)$. However, the effect sizes of the significant gender differences were rather small. Although female students judged repeated conventional transgressions as more wrong than male students, the difference was not significant and the effect size was small $(p=.07$, Cohen's $d=.17)$.

$<<$ Insert Table 2, about here $>>$

\section{Differences among Bullies, Victims, and Uninvolved Peers}

Differences among bullies, victims and uninvolved students in transgression judgments and justification of judgment in bullying and repeated conventional transgressions were analyzed using a series of one-way ANOVAs (see Table 3). Levine's test indicated that the assumption for equality of variances was violated for judgments of bullying, and moral reasons in bullying when testing group differences among bullies, victims, and those uninvolved. Therefore, Welch $F$ was used for these conditions.

A Welch $F$ indicated a main effect of bullying judgment across the groups. Bonferroni post hoc test procedures revealed that bullies were significantly less prone than victims to judge bullying as wrong $(p<.001$, Cohen's $d=1.38)$ or those uninvolved $(p<.001$; Cohen's $d=1.63)$. In addition, victims were significantly less likely to judge bullying as wrong than were uninvolved youth $(p=.038)$, although the effect size was rather small (Cohen's $d=.37)$. A oneway ANOVA indicated a main effect of judgment of repeated conventional transgressions across

the groups. Bonferroni post hoc test procedures revealed that bullies were significantly less likely to judge repeated conventional transgressions as wrong than were victims $(p<.001$, Cohen's $d=$ 1.09 ) or those not involved ( $p<.001$, Cohen's $d=1.18$ ). A Welch $F$ indicated a main effect of moral reasons when justifying judgment of bullying across the groups. Bonferroni post hoc test 
procedures revealed that bullies were significantly less prone to use moral reasons to justify their judgment of bullying than were victims ( $p<.001$; Cohen's $d=.97)$ and the uninvolved $(p<$ .001 ; Cohen's $d=1.17$ ).

$<<$ Insert Table 3, about here $>>$

\section{Discussion}

The present study examined whether children's judgments and reasoning to justify their judgments differ between bullying and repeated conventional transgressions. The study also examined whether there were gender differences and differences among bullies, victims and uninvolved children regarding their judgments and reasoning to justify their judgments. In accordance with our five first hypotheses, the findings showed that children judge bullying as more wrong than repeated conventional transgressions. Children also use moral reasons more frequently in their justifications of judging bullying than they do for repeated conventional transgressions. They use conventional reasons more frequently in their justifications of judgments of repeated conventional transgressions than for those of bullying. They use moral reasons more frequently than conventional reasons in their judgments of bullying, and use conventional reasons more frequently than moral reasons in their judgments of repeated conventional reasoning. Hence, the current findings support the distinction between morality and social convention assumed in the social domain theory (Nucci, 2001; Turiel, 1983) and previous research (Nucci, 2001) which found that children judge moral transgressions, including bullying (Thornberg, 2010; Thornberg et al., 2016) as more wrong than conventional transgressions. Children also tend to use moral reasons when justifying their judgments of moral transgressions and conventional reasons when justifying their judgments of conventional transgressions. As in Thornberg's (2010) and Thornberg and colleagues' (2016) studies, the vast majority of the 
children judge bullying as wrong, independently of the rules, and justify their bullying judgments by referring to the harm bullying causes.

\section{Role of Gender}

Three of our four hypotheses on gender differences (hypotheses 6, 8, and 9) were also supported by our findings. Female students judged bullying as more wrong and used moral reasons more frequently in their justifications of judgments of bullying than did male students. On the other hand, male students were more engaged in bullying than were female students. Thus, our findings significantly add to the literature on gender differences in moral reasoning and bullying. They support previous research showing that female students are less accepting than male students about breaking moral rules (Caravita, Giardino et al., 2012; Caravita, Gini, \& Pozzoli, 2012). Moreover, our findings confirm previous studies revealing that male students judge aggression as less wrong than do female students (Boulton et al., 1999; Rose \& Rudolph, 2006), but contradict other studies that found no gender differences in accepting moral transgressions (Banerjee et al., 2012; Caravita et al., 2009). Possible explanations for our findings might be that female students tend to have higher levels of affective empathy (Jolliffe \& Farrington, 2006a; Garaigordobil, 2009), moral sensitivity (for a meta-analysis, see You et al., 2011), and emotion recognition (Maguire et al., 2016) than do male students. Female students are also less likely to be morally disengaged (Gini et al., 2014). Female students' more frequent use of moral reasons when judging bullying and their stronger tendency to judge bullying as wrong could explain their lower prevalence of bullying, compared to male students.

In contrast to hypothesis 7 , female students in the present study did not judge repeated conventional transgressions as more wrong than male students. This result contradicts previous findings, which show that female students are less accepting than male students of breaking 
conventional rules (Caravita, Giardino et al., 2012; Caravita et al., 2009). Possible explanations for the inconsistent findings might concern cross-cultural or methodological differences among the studies. Another possible explanation for our current findings might, at least partly, be due to gender differences in affective empathy (Jollife \& Farrington, 2006a). Whereas moral transgressions like bullying appeal to empathy (Hoffman, 2000), conventional transgressions do not (Nucci, 2001). Although female students' higher levels of affective empathy should make them more inclined to judge moral transgressions as wrong as compared to male students, it should not influence their judgements of conventional transgressions. Further research is needed to deeply examine possible reasons for underlying gender similarities and differences in moral and conventional transgressions.

\section{Involvement in Bullying}

De Angelis and colleagues (2016) demonstrate that bullies judge both moral and conventional transgressions as less wrong than do their peers. Congruent with their study and with our hypotheses $10-11$, we found that bullies judge bullying and repeated conventional transgressions as less wrong than do victims or uninvolved peers. Bullies tend to bully others and also engage in oppositional and antisocial behavior more often than peers (Kljakovic \& Hunt, 2016). Our findings, together with those of De Angelis and colleagues (2016) indicate that this might be, at least in part, explained by bullies' greater acceptance of moral transgressions (including bullying) and conventional transgressions.

Moreover, and in line with our final hypothesis (12), bullies used moral reasons less frequently in their justifications of judgments of bullying than did either victims or uninvolved peers. This might, in turn, explain their greater acceptance of bullying, compared to their peers. The fact that bullies were less prone to refer to the victim's harm and judge bullying as wrong 
might indicate their inclination to morally disengage (Gini et al., 2014), and low levels of affective empathy (Jolliffe \& Farrington, 2006b). If children are more sensitive to the distress of victims, they would be more inclined to recognize and empathize with the victim's harm and suffering (Hoffman, 2000). Such sensitivity to social and emotion cues, as well as affective empathy, is, in turn, likely to influence the child's processing of information by priming and retrieving moral knowledge and values in the moral domain (cf., Arsenio \& Lemerise, 2004). Therefore, children would be more prone to use moral reasons and judge a moral transgression (bullying) as wrong, independent of whether rules in that particular context are present or absent (Nucci, 2001; Turiel, 1983). In contrast, higher levels of moral disengagement (Bandura, 2016) and less affective empathy (Jolliffe \& Farrington, 2006b) can reduce the likelihood of sensitivity to the victim's harm. Bullies' less frequent use of moral reasons when judging bullying, and their weaker tendency to judge bullying as wrong might explain why they are more likely to bully than are victims or uninvolved peers. Our findings may be comparable to a recent meta-analysis of cyberbullying which shows that cyberbullying perpetration is positively associated with aggressive cognition (e.g., moral approval of violence and positive attitudes towards aggressive behavior) and negatively associated with other-related cognition (Guo, 2016).

\section{Limitations}

Some limitations of this study should be noted. The variables are assessed through selfreporting, which might have inflated associations among them due to shared method variance. Moreover, the estimates might have been biased due social desirability and/or intentionally exaggerated responses (Cornell \& Bandyopadhyay, 2010). Second, because we opted for a crosssectional research design, we were unable to pinpoint the direction of the effects. To further expand these results, future research would need to adopt a longitudinal research design. Hence, 
identified associations, as well as causal conclusions based on these associations, need to be considered with great caution. Third, investigating how children respond to hypothetical scenarios is not the same as investigating how they actually respond to real-life situations. The ecological validity is therefore threatened (Cicourel 1982). However, the vignette technique is widely used in the literature because it enables researchers to collect responses from all of the participating children with regards to the same situations and to manipulate such situations experimentally (impossible to do in real-life). Indeed, some studies have demonstrated that children judge transgressions in real-life situations similar to in the way they react to hypothetical situations (e.g., Smetana, Schlagman, \& Adams, 1993), thus addressing concerns about ecological validity.

\section{Implications and Conclusion}

These limitations aside, the current findings have practical implications. Bullying prevention and intervention programs should address the moral deficit, found among bullies, of not linking bullying with its inherent harmful effects. Educational interventions targeting children's aggression "would be benefited by emphasizing 'moral training' to target immoral conceptions" (Kokkinos et al., 2016, p. 266), including the capacity of understanding the harm one's aggressive behavior inflicts on the victim and the concern for fairness and the welfare of others when judging behaviors toward them. The association between deficit or poor moral reasoning and aggression has been found in other studies (for meta-analyses, see Gini et al., 2014; Malti \& Krettenauer, 2013; cf., Van Vugt, Gibbs, Stams, Bijleveld, Hendriks, \& van der Laan, 2011). A disciplinary strategy that teachers, school psychologists and other school staff can use to promote empathy and moral development is induction. In induction, the adult explains why a certain behavior is unacceptable by emphasizing the other's perspective and pointing out 
the consequences of the misbehavior for others by drawing the attention to the harm or distress and making it clear that the child's action caused it (Hoffman, 2000). A teacher, school psychologist or school counselor might say, for example, "How would you feel if someone did that to you?", "You really hurt Sarah and made her sad when you all run away from her", and "How do you think Pete felt when you pushed him down in front of the others?" Induction encourages empathy, harm-effect moral reasoning, and other-oriented moral concerns (Hoffman, 2000). There is a need to educate all students to firmly recognize bullying as a moral transgression by making them sensitive to others' well-being, victims' suffering, and the harmful consequences of all forms of bullying. Thus, school psychology and teacher training programs should emphasize moral development and education as a part of understanding and counteracting school bullying.

School psychologists should advocate and promote a positive moral atmosphere in the school and a prosocial moral development among students by their participation in school-based anti-bullying teams, consultations with educators and direct interventions with bullies. A positive moral atmosphere in schools and classrooms with warm, caring and just relationships among students and between teachers and students has been found to be associated with greater moral development (Power \& Higgins-D’Alessandro, 2006; Watson, 2014) and less bullying and peer victimization (Konold et al., 2014; Thornberg, Wänström, \& Pozzoli, 2017). With reference to Watson (2014), crucial components for building a positive moral atmosphere in schools and classrooms that promote moral competence and prosocial behavior are: (a) warm, caring, supportive and mutually-trusting teacher-student relationships; (b) classrooms that are characterized as caring and democratic in which each student's needs for competence, autonomy, and belonging are met; (c) opportunities for students to discuss, develop and refine their 
understanding of moral values and how to integrate them into everyday school life; and (d) teachers who give structure, guidance, and proper responses to misbehavior, particularly by induction and reasoning. Developmental Discipline (earlier termed "Child Developmental Project") is a program that is based on these four components (Watson, 2014) and has been found to have positive effects on students' social and moral development (Battistich, 2003; Battistich, Schaps, \& Wilson, 2004). Building a caring community with a positive moral atmosphere by including induction as a significant discipline strategy could be considered as a vital component of bullying prevention as it promotes students' moral competence and compassion. Finally, with reference to the significant gender differences found in the present study, there appears to be a need to individualize bullying prevention and interventions by gender. However, these findings are still not clear or conclusive and future research should further examine this aspect. 


\section{Compliance with Ethical Standards}

Conflict of Interest The authors declare that they have no conflict of interest.

Research involving human participants All procedures performed were in accordance with the ethical standards of the national research committee and with 1964 Helsinki declaration and its later amendments. The study received ethical approval from the Regional Ethical Review Board at Linköping.

Informed consent Informed consent was obtained from all individual participants included in the study. In addition, parental consent was obtained for all individual participants in the study. 


\section{References}

Arsenio, W. F., \& Lemerise, E. A. (2004). Aggression and moral development: Integrating social information processing and moral domain models. Child Development, 75, 987-1002. doi: $10.1111 / \mathrm{j} .1467-8624.2004 .00720 . x$

Baker, K. (2013). Conduct disorders in children and adolescents. Paediatrics and Child Health, 23, 24-29. Doi: 10.1016/j.paed.2012.09.007

Bandura, A. (2016). Moral disengagement: How people do harm and live with themselves. New York, NY: Worth.

Banerjee, R., Bennett, M., \& Luke, N. (2012). Children's reasoning about self-presentation following rule violations: The role of self-focused attention. Child Development, 83, 1805-1821. doi: 10.1111/j.1467-8624.2012.01813.x

Battistich, V. (2003). Effects if a school-based program to enhance prosocial development on children's peer relations and social adjustment. Journal of Research on Character Education, 1, 1-17.

Battistich, V., Schaps, E., \& Wilson, N. (2004). Effects of an elementary school intervention on students" "connectedness" to school and social adjustment during middle school. Journal of Primary Prevention, 24, 243-262. doi: 10.1023/B:JOPP.0000018048.38517.cd

Boulton, M. J., Bucci, E., \& Hawker, D. S. (1999). Swedish and English secondary school pupils' attitudes towards, and conceptions of, bullying: Concurrent links with bully/victim involvement. Scandinavian Journal of Psychology, 40, 277-284. doi: $10.1111 / 1467-9450.404127$ 
Caravita, S. C. S., Miragoli, S., \& Di Blasio, P. (2009). "Why should I behave in this way?" Rule discrimination within the school context related to children's bullying. In L. R. Elling (Ed.), Social development (pp. 269-290). New York: Nova Science Publishers.

Caravita, S C. S., Giardino, S., Lenzi, L., Salvaterra, M., \& Antonietti, A. (2012). Socioeconomic factors related to moral reasoning in childhood and adolescence: The missing link between brain and behavior. Frontiers in Human Neuroscience, 6, Art. 262. doi: $10.3389 /$ fnhum.2012.00262

Caravita, S. C. S., Gini, G., \& Pozzoli, T. (2012). Main and moderated effects of moral cognition and status on bullying and defending. Aggressive Behavior, 38, 456-468. doi: 10.1002/ab.21447

Cicourel, A. V. (1982). Interviews, survey, and the problem of ecological validity. American Sociologist, 17, 11-20.

Cook, C. R., Williams, K. R., Guerra, N. G., Kim, T. E., \& Sadek, S. (2010). Predictors of bullying and victimization in childhood and adolescence: A meta-analytic investigation. School Psychology Quarterly, 25, 65-83. doi: 10.1037/a0020149

Cornell, D. G., \& Bandyopadhyay, S. (2010). The assessment of bullying. In S. R. Jimerson, S. M. Swearer, \& D. L. Espelage (Eds.), Handbook of bullying in schools: An international perspective (pp. 265-276). New York, NY: Routledge.

De Angelis, G., Baccini, D., \& Affuso, G. (2016). The mediating role of domain judgement in the relation between the Big Five and bullying behaviours. Personality and Individual Differences, 90, 16-21. doi: 10.1016/j.padi.2015.10.029

Farrington, D. P., Lösel, F., Ttofi, M. M., \& Theodorakis, N. (2012). School bullying, depression and offending behaviour later in life. Stockholm: National Council for Crime Prevention. 
Garaigordobil, M. (2009). A comparative analysis of empathy in childhood and adolescence: Gender differences and associated socio-emotional variables. International Journal of Psychology and Psychological Therapy, 9, 217-235.

Gini, G., \& Pozzoli, T. (2013). Bullied children and psychosomatic problems: A meta-analysis. Pediatrics, 132, 720-729.

Gini, G., Pozzoli, T., \& Hymel, S. (2014). Moral disengagement among children and youth: A meta-analytic review of links to aggressive behavior. Aggressive Behavior, 40, 56-68. doi: $10.1002 / \mathrm{ab} .21502$

Guo, S. (2016). A meta-analysis of the predictors of cyberbullying perpetration and victimization. Psychology in the Schools, 53, 432-453. doi: 10.1002/pits.21914

Hall, W. A., Long, B., Bermbach, N., Jordan, S., \& Petterson, K. (2005). Qualitative teamwork issues and strategies: Coordination through mutual adjustment. Qualitative Health Research, 15, 394-410. doi: 10.1177/1049732304272015

Hoffman, M. (2000). Empathy and moral development: Implications for caring and justice. Cambridge: Cambridge University Press.

Jolliffe, D., \& Farrington, D. P. (2006a). Development and validation of the Basic Empathy Scale. Journal of Adolescence, 29, 589-611. doi: 10.1016/j.adolescence.2005.08.010

Jolliffe, D., \& Farrington, D. P. (2006b). Examining the relationship between low empathy and bullying. Aggressive Behavior, 32, 540-550. doi: 10.1002/ab.20154

Kljakovic, M., \& Hunt, C. (2016). A meta-analysis of predictors of bullying and victimisation in adolescence. Journal of Adolescence, 49, 134-145. doi:

10.1016/j.adolescence.2016.03.002 
Kokkinos, C. M., Voulgardidou, I., Mandrali, M., \& Parousidou, C. (2016). Interactive links between relational aggression, theory of mind, and moral disengagement among early adolescents. Psychology in the Schools, 53, 253-269. doi: 10.1002/pits.21902

Konold, T., Cornell, D., Huang, F., Meyer, P., Lacey, A., Nekvasil, E., Heilbrun, A., \& Shukla, K. (2014). Multilevel multi-informant structure of the Authoritative School Climate Survey. School Psychology Quarterly, 29, 238-255. doi: 10.1037/spq0000062

Lakens, D. (2013). Calculating and reporting effect sizes to facilitate cumulative science: A practical primer for $t$-tests and ANOVAs. Frontiers in Psychology, 4, 1-12 [863]. doi: 10.3389/fpsyg.2013.00863

Maguire, L. K., Niens, U., McCann, M., \& Connolly, P. (2016). Emotional development among early school-age children: Gender differences in the role of problem behaviours. Educational Psychology, 36, 1408-1428. doi: 10.1080/01443410.2015.1034090

Malti, T., \& Krettenauer, T. (2013). The relation of moral emotion attributions to prosocial and antisocial behavior: A meta-analysis. Child Development, 84, 397-412. doi: 10.1111/j.1467-8624.2012.01851.x

Nucci, L. P., \& Herman, S. (1982). Behavioral disordered children's conceptions of moral, conventional, and personal issues. Journal of Abnormal Child Psychology, 10, 411-426. doi: $10.1007 / \mathrm{BF} 00912330$

Nucci, L. P. (2001). Education in the moral domain. Cambridge: Cambridge University Press. Nucci, L. P., \& Weber, E. K. (1995). Social interactions in the home and the development of young children's conceptions of the personal. Child Development, 66, 1438-1452. doi: 10.1111/j.1467-8624.1995.tb00944.x 
Olweus, D. (1996a). Frågeformulär om mobbning till elever - QSO5Se. Bergen: University of Bergen.

Olweus, D. (1996b). Questionnaire on bullying for students - QE06. Bergen: University of Bergen.

Power, F. C., \& Higgins-D’Alessandro, A. (2006). The just community approach to moral education and the moral atmosphere of the school. In L. P. Nucci \& D. Narvaez (Eds.), Handbook of moral and character education (pp. 230-247). New York, NY: Routledge.

Reijntjes, A., Kamphuis, J. H., Prinzie, P. \& Telch, M. J. (2010). Peer victimization and internalizing problems in children: A meta-analysis of longitudinal studies. Child Abuse \& Neglect, 34, 244-252. doi: 10.1016/j.chiabu.2009.07.009

Rose, A. J., \& Rudolph, K. D. (2006). A review of sex differences in peer relationship processes: Potential trade-offs for the emotional and behavioral development of girls and boys. Psychological Bulletin, 132, 98-131. doi: 10.1037/0033-2909.132.1.98

Smetana, J. G., Schlagman, N., \& Adams, P. W. (1993). Preschool children's judgments about hypothetical and actual transgressions. Child Development, 64, 202-214. doi:

10.1111/j.1467-8624.1993.tb02904.x

Solberg, M. E., \& Olweus, D. (2003). Prevalence estimation of school bullying with the Olweus bully/victim questionnaire. Aggressive Behavior, 29, 239-268. doi: 10.1002/ab.10047

Swedish National Agency for Education (2016). Attityder till skolan [Attitudes toward school] (Report 438). Stockholm: Wolters Kluwers.

Thornberg, R. (2010). A study of children's conceptions of school rules by investigating their judgments of transgressions in the absence of rules. Educational Psychology, 30, 583603. doi: 10.1080/01443410.2010.492348 
Thornberg, R., Birberg Thornberg, U., Alamaa, R., \& Daud, N. (2016). Children's conceptions of bullying and repeated conventional transgressions: Moral, conventional, structuring, and personal-choice reasoning. Educational Psychology, 36, 95-111. doi:

$10.1080 / 01443410.2014 .915929$

Thornberg, R., Wänström, L., \& Pozzoli, T. (2017). Peer victimisation and its relation to class relational climate among school children. Educational Psychology, 37, 524-536. doi: $10.1080 / 01443410.2016 .1150423$

Turiel, E. (1983). The development of social knowledge: Morality and convention. Cambridge: Cambridge University Press.

Van Vugt, E., Gibbs, J., Stams, G. J., Biljeveld, C., Hendriks, J., \& van der Laan, P. (2011). Moral development and recidivism: A meta-analysis. International Journal of Offender Therapy and Comparative Criminology, 55, 1234-1250. doi:

$10.1177 / 0306624 X 11396441$

Watson, M. (2014). Developing discipline and moral education. In L. Nucci, D. Narvaez, \& T. Krettenauer (Eds.), Handbook of moral and character education (2 $2^{\text {nd }}$ ed., pp. 159-179). New York, NY: Routledge.

You, D., Maeda, Y., \& Bebeau, M. J. (2011). Gender differences in moral sensitivity: A metaanalysis. Ethics and Behavior, 21, 263-282. doi: 10.1080/10508422.2011.585591 


\section{Table 1}

Moral and conventional reasons

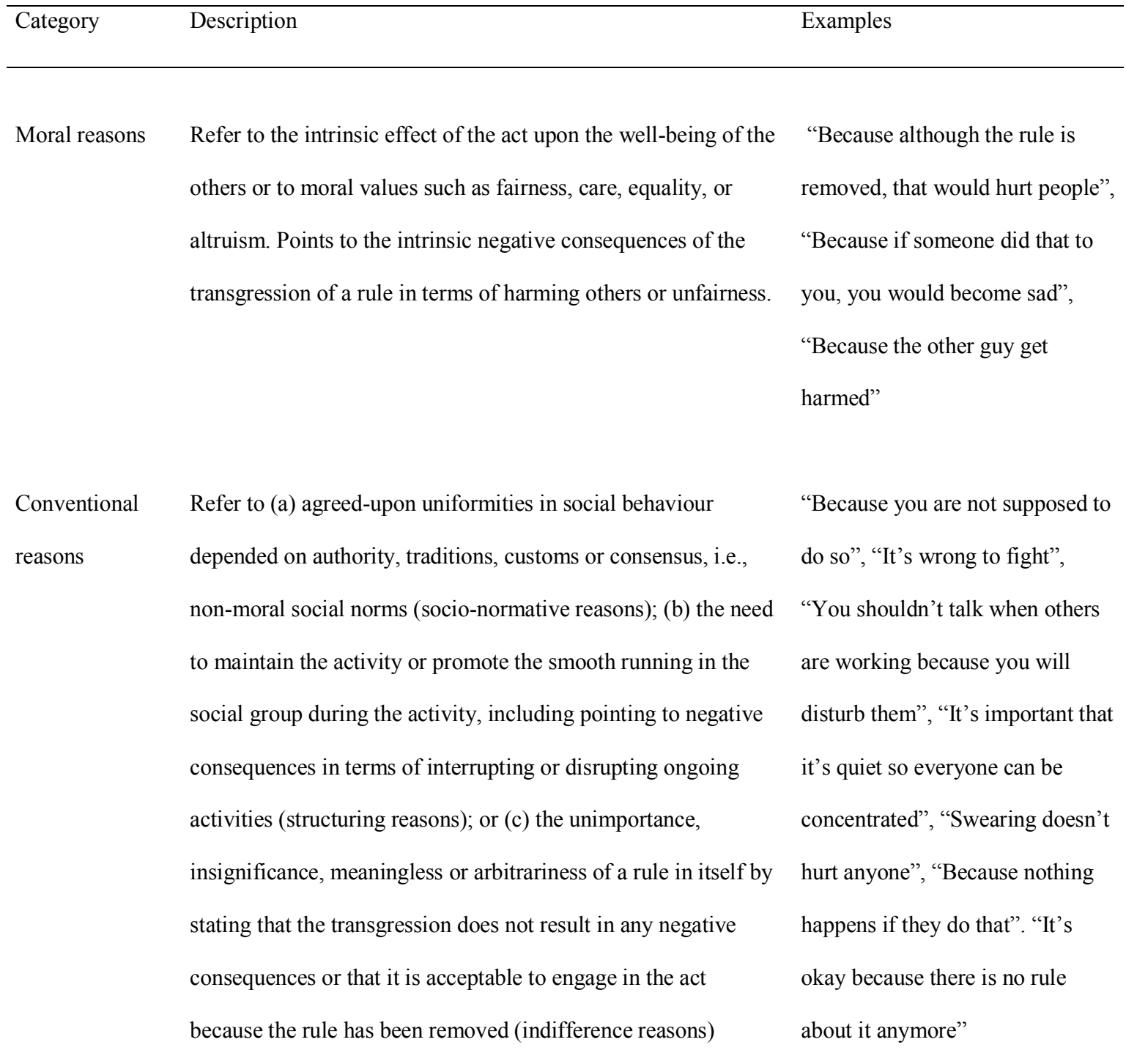

This is a revised version of Thornberg (2010, p. 590). The examples are from the current data. 
Table 2

Gender differences in all variable (one-way ANOVAs)

\begin{tabular}{llllll}
\hline Variables & Females: & Males: & $F$ & $p$ & Cohen's $d$ \\
& $M(S D)$ & $M(S D)$ & & & \\
& & & & & \\
\hline Bullying judgment & $3.76(.28)$ & $3.58(.50)$ & $18.71^{\mathrm{a}}$ & $<.001$ & .44 \\
Conv. transgr. judgment & $2.36(.79)$ & $2.22(.85)$ & 3.28 & .071 & .17 \\
Moral reasons in bullying & $3.02(1.01)$ & $2.60(1.27)$ & $12.38^{\mathrm{a}}$ & $<.001$ & .36 \\
Bullying & $.10(.24)$ & $.24(.43)$ & $14.04^{\mathrm{a}}$ & $<.001 .38$
\end{tabular}

Note: ${ }^{\mathrm{a}}=$ Welch $F$ 
Table 3

Differences between bullies, victims and uninvolved regarding transgression judgments and judgment justifications (one-way ANOVAs)

\begin{tabular}{llllll}
\hline Variables & $\begin{array}{l}\text { Bullies } \\
M(S D)\end{array}$ & $\begin{array}{l}\text { Victims } \\
M(S D)\end{array}$ & $\begin{array}{l}\text { Uninvolved } \\
M(S D)\end{array}$ & $F$ & $p$ \\
\hline Bullying judgment & $2.90(.67)$ & $3.64(.34)$ & $3.76(.31)$ & $56.93^{\mathrm{a}}$ & $<.001$ \\
Conv. transgr. judgment & $1.36(.97)$ & $2.31(.77)$ & $2.39(.76)$ & 16.50 & $<.001$ \\
Moral reasons in bullying & $1.53(1.36)$ & $2.77(1.18)$ & $2.95(1.05)$ & $10.05^{\mathrm{a}}$ & $<.001$ \\
\hline
\end{tabular}

Note: ${ }^{\mathrm{a}}=$ Welch $F$ 